EINSTELLUNGSUNTERSUCHUNG

\section{Ist eine Röntgen-Thorax-Aufnahme heute noch sinnvoll?}

- Bei Personen, die im Gesundheitsberufen tätig werden wollen, wird im Allgemeinen eine Einstellungs-Röntgen-Thorax-Aufnahme verlangt, insbesondere bei positivem Tuberkulin-Hauttest. Ob ein solches Vorgehen allerdings noch sinnvoll ist, wurde in einer Studie bei 2586 asymptomatischen Personen untersucht.

Nur bei 6,1\% der Röntgen-Thorax-Aufnahmen fand sich ein pathologischer Befund, und zwar fast ausschließlich im Sinne alter spezifischer Veränderungen. „Bei niemandem wurde eine aktive Tuberkulose diagnostiziert“, so Univ.-Prof. Dr. Gerhard Mostbeck, Wien. Die häufigsten Veränderungen waren Lymphknotenverkalkungen, Kuppenschwielen, fibrös-narbige Veränderungen und nicht verkalkte Rundherde. „Das EinstellungsThorax-Röntgen ist somit wenig hilfreich, um eine bisher nicht erkannte aktive Tuberkulose zu erfassen“, so Mostbeck.

Doch es gebe gute Gründe im Rahmen der Einstellungsuntersuchung bei Personen mit positivem Tuberkulin-Test am Thorax-Röntgen festzuhalten. Der Nachweis alter spezifischer Residuen erlaube eine Abschätzung des Risikos für eine Reaktivierung. Die Röntgen-Thorax-Aufnahme bei der Einstellung sei außerdem eine wichtige Basisuntersuchung für eventuell später notwendige Verlaufskontrollen, falls die Person mit einem Tbc-Patienten konfrontiert werde.

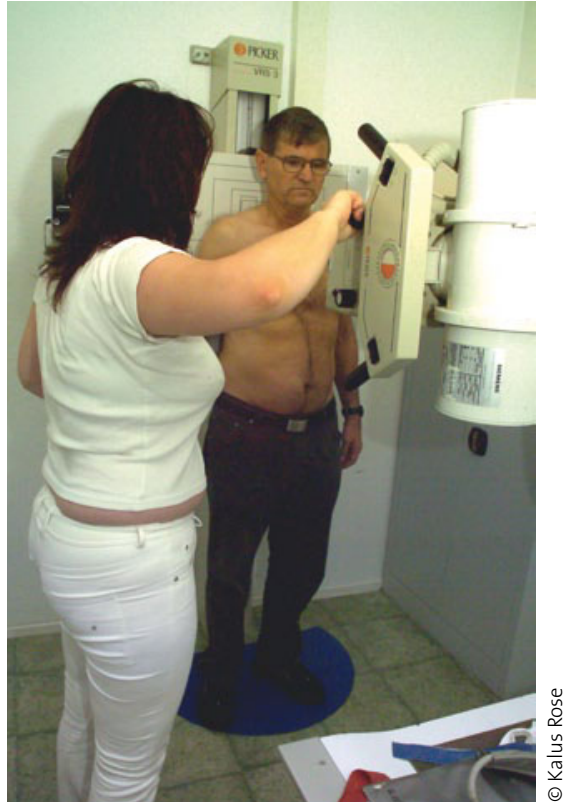

Praktisch nie wird eine bisher unbekannte aktive Tbc entdeckt.
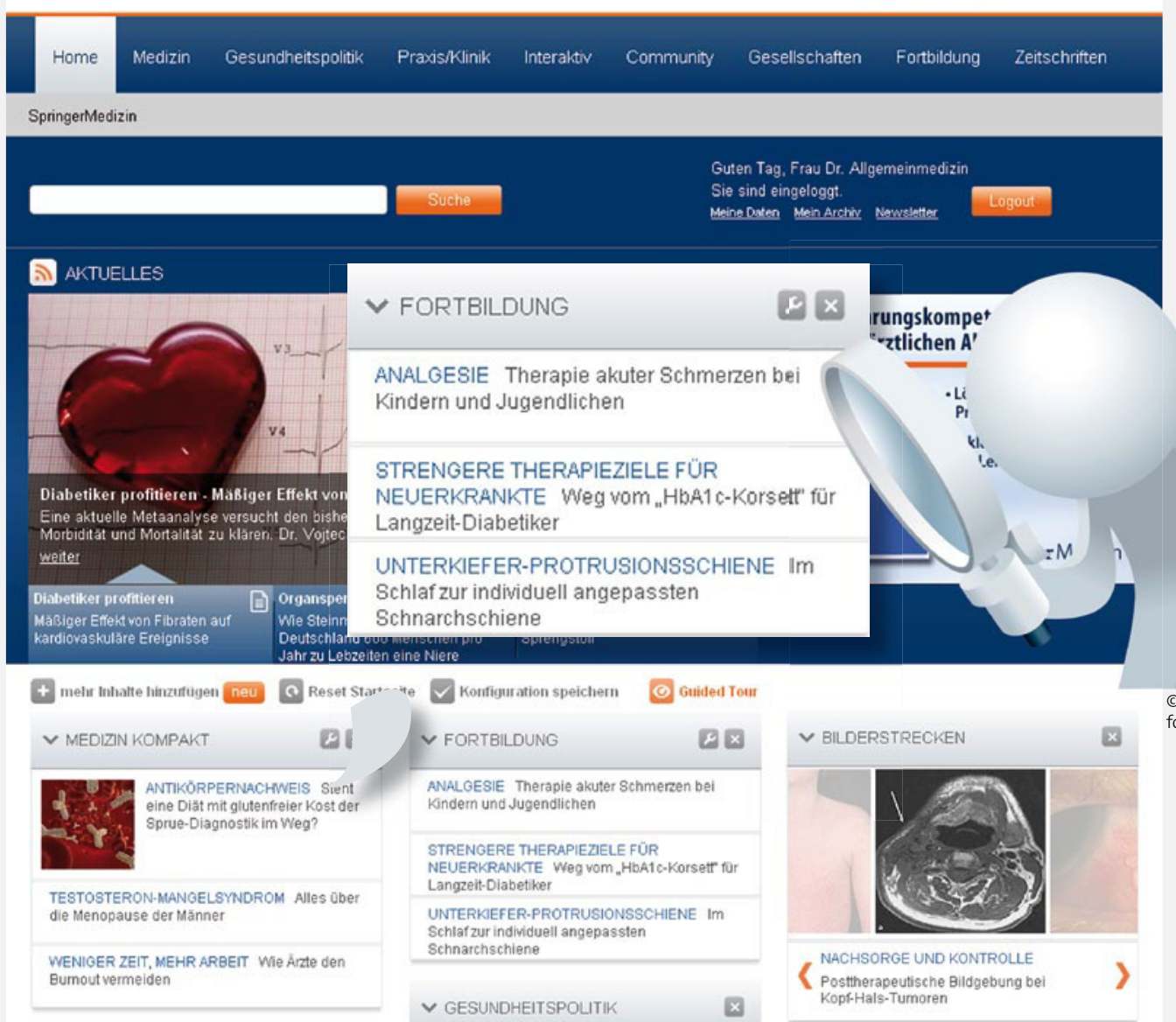

Fortbilden wird auf SpringerMedizin.de, dem Fachportal für Ärzte, groß geschrieben. In diesem Bereich finden Sie nicht nur CME-Module samt Link zum Punkten, sondern auch interessante Originalarbeiten und spannende Kasuistiken aus dem gesamten Springer-Fachzeitschriften-Pool. Alle diese Fachinhalte sind natürlich Ärzten vorbehalten und passwortgeschützt. Wer sich bei der Registrierung mit seinem Fachgebiet anmeldet, erhält über die maßgeschneiderte Startseite gleich die auf seine Spezialität zugeschnittenen Beiträge. Der Weg dorthin ist einfach: Im Portlet „Fortbildung“ fin-

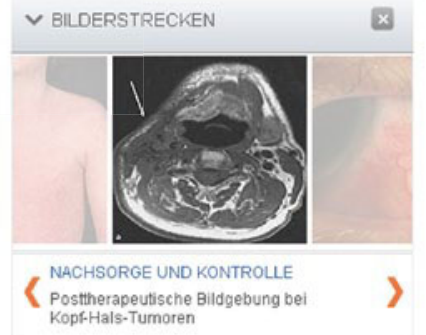
den Sie die jeweils aktuellsten Fortbildungsinhalte. Über den

() vuifah/ fotolia.com

Navigationspunkt „Fortbildung" in der blauen Leiste steuern Sie das Komplettangebot von $\mathrm{CME}$, Kasuistiken und Originalarbeiten an oder sortieren mit Hilfe des Pulldown-Menüs, welches Fachgebiet und welche Beitragsart die Treffer sein sollen. Viel Erfolg! 